\title{
Optimization of Knowledge Management Processes through Benchmarking in Organizations
}

\author{
Dr. Irena Figurska \\ Pomeranian University, Westerplatte 64, 76-200 Słupsk, Poland \\ Email: irenafigurska@vp.pl \\ Dr. Aneta Sokół \\ University of Szczecin, Cukrowa 8, 71-004 Szczecin, Poland \\ Email: aneta.dorota@wp.pl
}

Doi:10.5901/mjss.2014.v5n27p235

\begin{abstract}
Today, knowledge as a strategic resource and its competent management are becoming increasingly important for the competitiveness of organizations. According to process approach to knowledge management (KM) the success of KM derives from the effectiveness of individual KM processes. One of the methods to increasing effectiveness of knowledge management is to optimize its processes by benchmarking and this issue is the subject of presented article. The paper describes knowledge management processes and their specificity as well as benchmarking as a method for their optimization. In the later parts of the paper presented is the path leading from the vision and goals of an organization, via a decision to optimize KM processes by benchmarking and finally the framework of knowledge management processes benchmarking. The final part presents results of a survey conducted among Polish organizations on issues related to benchmarking of knowledge management processes.
\end{abstract}

Keywords: knowledge; knowledge management; process; optimization; benchmarking

\section{Introduction}

Nowadays a tremendous increase in the interest in issues related to building a knowledge-based economy is observed. Numerous books and articles deal with the issue and as many conferences, seminars, trainings and workshops are being organized. In a knowledge-based economy the competitiveness of a given organization is based on knowledge and experience of its employees, therefore the economists, management theorists and practitioners turn their attention to intangible assets - mainly to knowledge.

Knowledge is an unique resource, externalized in many different ways and of various forms. It exists in people's minds and manifests itself in: products, services, processes, instructions, and regulations. It is reflected in people's behaviours, attitudes and values, and is present in networks of relationships. The word knowledge is commonly used in everyday language, but only a few are able to precisely define the concept.

Nowadays, achieving success in turbulent environments requires organizations to make wise decisions and to take actions based on relevant knowledge, which should be appropriate managed. Increase in popularity of KM-related organizational projects stems from many factors of intrapreneurship capacity (unsuitable organizational culture, lack of organizational memory, improper work organization, restructuring, reductions, personnel fluctuation etc.) as well as factors resulting from external conditions (globalization, labour market changes, growth of both knowledge and information, the development of information technology, competition, etc.).

Although KM is increasingly popular in businesses and scientific circles, a generally-acceptable definition has not been formulated so far (Sarvary, 1999; Wiig, 1993; Probst, 2004; Skyrme, 2003; Murray and Myers, 1997). For the purpose of this paper, knowledge management is defined as a set of: systematic, organized, thoughtful, and flexible activities undertaken and performed with the intention of achieving the objectives of the organization in an efficient and effective manner. These activities are focused on corporate knowledge resources (individual, collective, organizational, explicit, and tacit) and enable implementation of processes associated with knowledge (localization, acquisition, development, sharing, preservation, and use of knowledge) as well as the shape of the environment (human, technical, cultural) favourable to KM. In these activities appropriate methods and tools are used (Figurska, 2012).

The major knowledge management objective is to enable organizations to act intelligently (Wiig, 1999). Detailed 
KM objectives can be related to: knowledge management processes, methods, tools, procedures as well as people, culture of the organization, and other elements of the KM system.

Properly managed knowledge can increase: productivity of the organization, financial performance, innovation, staff performance, work relationships, and customer satisfaction. It brings benefits to employees (helps them to perform their jobs and saves time through better decision-making and problem-solving, builds a sense of community bonds in the company, helps them to keep up to date, provides challenges and opportunities to contribute), teams (develops professional skills, promotes peer-to-peer mentoring, facilitates more effective networking and collaboration, develops a professional code of ethics and common language) and the organization (helps to drive strategy, solves problems quickly, diffuses best practices, improves knowledge embedded in products and services, creates ideas, increases opportunities for innovation, enables to achieve better competitive position, builds organizational memory) (Dalkir, 2005).

Knowledge management is often perceived and described in context of its processes and their effectiveness. Therefore, further part of this paper focuses on process approach to knowledge management.

\section{Process Approach to Knowledge Management}

\subsection{Knowledge management processes}

Process approach is called a new philosophy of management, which emerged from the need to improve management efficiency and striving for increase in customer satisfaction. Organizations are viewed as a combination of highly integrated processes which are seen as valuable assets requiring investment and development (Hammer and Champy, 1993; Hammer, 1999; Lockamy and McCormack, 2004). Identification of processes allows organizations for a better understanding of value creation.

The process approach to knowledge management is basically practical which it owes to the achievements of consulting companies in terms of both the development of the KM approach itself and practical solutions which enable to and/or facilitate the ability to particular KM processes realization. According to this approach KM is perceived as a set of processes that enable creation, popularization and use of knowledge to achieve goals of the organization.

The process of knowledge management is a logically ordered sequence of operations based on and performed on knowledge, leading to achieving the assumed results satisfying needs of customers of the process. The major objective of applying KM processes is not only to assure that knowledge is provided the right person in the right time, but also to enable all the people who need that knowledge to use it in practice so that they could solve problems easier, better and more quickly, or could simply avoid them.

One can find different classifications of knowledge management processes in the literature, however the most frequently cited by other authors classification divides KM processes into: acquisition, development, sharing and distributing, applying, preservation and localization of knowledge (Probst, Raub and Romhardt, 2002).

Organization that does not possess the knowledge necessary to make specific decisions and take specific actions can acquire it from external environment. Knowledge from some external sources (e.g. Internet, informal contacts) can be acquired relatively easy and at a relatively low cost. However acquiring certain knowledge resources is connected with the necessity of buying it on the knowledge markets (Probst, Raub and Romhardt, 2002). There are many ways of acquiring knowledge from external sources, which include among others: use the service of knowledge brokers, employment of new workers, use the service of consulting firms, mergers and takeovers, strategic alliances, personal contacts or market research, contacts with scientists, research centres and institutions of higher education, taking form of joint research projects, sponsoring research, etc., media, benchmarking, external trainings, subscription of specialist magazines, business intelligence as well as use of products connected with knowledge which include: intellectual property rights (mainly patents), software, plans, projects, samples, etc. (Probst, Raub and Romhardt, 2002; Kowalczyk and Nogalski, 2007). It is worth mentioning that knowledge acquired from the environment is strongly dependent on the context in which it is used, therefore transferring it from one company to another may decrease the possibility of its further effective use.

The process of knowledge development in the company consists in increasing the number of abilities, introducing new products, more favorable solutions and more effective mechanisms (Probst, Raub and Romhardt, 2002). The basis for the company's knowledge development is development of knowledge of each employee, which can be defined as a long-term process during which employee's knowledge in both theoretical and practical dimension is a subject to deepening and broadening, thanks to which the employee can meet the requirements set by widely understood environment (internal, external) and solve problems emerging in the organization effectively. Knowledge development occurs when the learner has mastered the ability to function at a new, higher level permanently (Figurska, 2007). For the 
inclusion of individual employees' knowledge into a collective process of knowledge development it is necessary to: communicate, interact, integrate and secure the transparency of resources (Probst, Raub and Romhardt, 2002).

Knowledge sharing consists in transferring knowledge by both employee's participation in the communication process and cooperation. It can be done by means of both formal and informal channels. Sharing knowledge can be in a form of centrally managed process within a given group of employees or it can be a transfer of knowledge among people or teams of employees (Probst, Raub and Romhardt, 2002). Knowledge dissemination includes activities aimed at making a given resource accessible. This process can be performed through: advertising, brochures, creating Internet websites informing about the organization and its product, describing or presenting case studies or best practices, etc. (Mikuła, 2006). To transfer knowledge effectively people should possess the ability to share knowledge, know methods of knowledge sharing and be motivated to participate in this process. Sharing knowledge is a difficult process, that is why it is worth using techniques that facilitate this process, such as: database of best practices, appropriately designed office space, knowledge fairs, communities of practice, document management, corporate portal, interdisciplinary teams and knowledge centres (Skyrme, 2002).

Using knowledge in activities is an ultimate stage of knowledge management. Using knowledge consists in translating it into activities through making right decisions and reflecting it in products, services, procedures etc. The realization of this process increases the value of knowledge, thus increasing the value of the company itself. However, there are some barriers of knowledge use, such as: talking replaces action, memory replaces thinking, fear prevents the use of knowledge, performance measurement system hinders its appropriate evaluations and competition turns friends into enemies (Pfeffer and Sutton, 2002). To use knowledge effectively, the treatment methods must accent collaboration, freedom to act and feelings of responsibility for the outcome in teams and their members. Summing up, knowledge which is not implemented in practice is useless for the organization. As far as competitive advantage is concerned it is important not only to use knowledge in general but to use it better and faster than competitors.

To avoid a problem of loosing a previously acquired knowledge companies should be involved in the process of knowledge preservation. Its realization requires defining what knowledge should be preserved, how it should be stored, enlarged and who should be responsible for it, how knowledge should be retrieved and how to eliminate outdated knowledge.

The realization of knowledge preservation requires activation of the following processes: knowledge selection, storage and organizational memory update (Probst, Raub and Romhardt, 2002). Knowledge selection requires the creation of criteria for knowledge and information evaluation as well as for verification of their validity for the organization. Verified knowledge and information should be analyzed and interpreted, which lead to bridging knowledge gaps in the organization. Organizational knowledge can be stored in five repositories, namely: employees, culture, procedures, formalized systems and structures, as well as the environment of the organization (Walsh and Ungson, 1999). Knowledge which is to be stored must be codified. The realization of this process is enabled by the development of IT tools, which facilitate access to information, its verification, segregation etc.

Knowledge becomes outdated quickly, what means that employees should update knowledge regularly. Knowledge update requires the process of developing and acquiring knowledge, and at the same time unnecessary sources of knowledge must be eliminated to make space for new knowledge and new experiences.

To increase effectiveness of knowledge management, knowledge sources must be located and presented. Knowledge localization is aimed at showing where the sources of knowledge are to enable employees to use them. The main internal knowledge sources are: employees, documents (instructions, regulations, manuals, annual reports, business plans, financial statements, marketing plans, development plans, address lists etc.) and organizational culture, which shows values, norms and habits that are acceptable and desired in the company. These knowledge sources are necessary to make right decisions and actions in the company. External sources of knowledge include: clients, suppliers, business environment, research centres, institutions of higher education, conferences, seminars, exhibitions, market research agencies, publications, consulting firms, knowledge brokers, business competitors, politicians, media, the Internet, best practices, employees' informal contacts and others. Not all external sources of knowledge are equally important to the organization, therefore only sources providing the organization with knowledge that meets its needs should be localized.

In order to ensure transparency of knowledge sources it is advisable to visualize them. The most popular methods of knowledge visualization are: address books, communication networks, metaphors and knowledge maps.

To summarize, there are many potential sources of knowledge, both in the organization and outside it. What is taken into consideration while choosing a given source is its credibility, ability to adjust to the informational needs of an entity and the form of its presentation. 


\subsection{Specificity of knowledge management processes}

Knowledge management processes largely depends on the nature of the company's activity, specificity of the industry, as well as knowledge strategy and KM strategy. A characteristic feature of knowledge management processes is that they relate to certain activities performed on knowledge, which is - as it was already stated - a specific resource. Knowledge is predominant to other resources, occurs simultaneously, is inexhaustible and non-linear, is relative, ambiguous, dynamic, intangible and elusive, becomes outdated quickly, can be created in various ways, and making a full use of knowledge is a difficult task. The specificity of knowledge as a resource is reflected in the characteristics of the processes relating to knowledge and their management.

In case of KM processes it is difficult, and sometimes even impossible, to determine the direct recipient of the process, that formulates requirements and uses the results of the process. Since it is difficult to predict the effects of actions aimed at knowledge development, transferring and using, it may be that the beneficial recipient of the process is not the one who was supposed to be.

Due to the immateriality of knowledge, determination of the measurable goals of the KM processes as well as measurement of their effects can cause problems too. The literature presents methods of knowledge measurement which are verified in practice, this issue, however, is not the subject of this article.

It is also difficult to determine a kind of knowledge which determines a competitive advantage of the organization and should be the subject of KM processes. In case of knowledge management processes, proper determination of their subject requires a creation of knowledge strategy, which is derived from the role that knowledge plays in the organization (the most important source of competitive advantage of the company, a way to improve goods and services, the core business of the organization, a way to improve processes).

Sometimes determination of parameters of the process, in particular its duration, creates some problems. For example, in case of the process of knowledge development it should be remembered that this process is non-linear, which means that sometimes knowledge development occurs rapidly, and sometimes growth of knowledge is slow and difficult to observe.

It is also not easy to develop a structure of the KM process, that is to distinguish sub-processes, activities, and other elementary components of the process. The reason for this is that activities performed on knowledge not always and not fully submit to the structuring.

In practice, realization of knowledge management processes faces a lot of barriers, among which the most important are: insufficient knowledge resources within an organization, lack of benefits connected with the realization of KM processes, perceiving knowledge as property or/and as a source of power, lack of conditions for the realization of KM processes, lack of superiors' support in the realization of KM processes, lack of purpose understanding, for which knowledge management processes serve, lack of access to knowledge sources, lack of skills at management of knowledge processes and lack of knowledge, how to manage knowledge (Figurska, 2009). Knowledge of these barriers helps organizations to deal with them effectively.

\section{Benchmarking of Knowledge Management Processes}

\subsection{Benchmarking as method for process optimization}

Process optimization can be defined as a reaching an optimal form of a process, that is the best possible in given circumstances. Analyzing this both simple and very broad definition, it is worthwhile to pay attention to a number of issues, such as: 1) identification of a feasible sets of process variants is the base for the selection of one of them based on assessment carried out; 2) assessment of individual process variants requires determination of the criterion/criteria for their evaluation; 3) the selected evaluation criteria (cost, profit, duration, customer satisfaction, sales volume, etc.) depends on the purpose the process serves; 4) selection of evaluation criteria is the starting point for selection (or development) of appropriate measures that allow for determination of the actual state of the variable to be assessed as well as the degree to which the set goals are achievable; 5) conditions, that is elements of widely understood environment that have significant impact on the process undergoing optimization, should be constantly monitored and taken into consideration when setting criteria for the evaluation of individual process variants.

Process optimization refers to both: the process logic (what is done and why) and the individual tasks and their effectiveness (how it is done). It enables companies to increase the effectiveness of their functioning and to flexibly match the changing business environment. Process optimization results in increasing the organization's ability to achieving goals set in its different operating areas. If a company is able to achieve its goals better and quicker than competitors, its 
competitiveness increases. One of the methods used in process optimization is benchmarking, which became a standard operating procedure in the 1980s and has been successfully used by many organizations to improve their performance. Literature provides many definitions of benchmarking (Blakeman, 2002; Kelessidis, 2000; Wood, 2009) that indicate what benchmarking is (the process), what its nature is (continuous, systematic), how it works (search for the best solutions) and what effects are expected from it (improvement of organization's functioning). The authors of this paper propose their own definition of benchmarking and see it as a continuous process of learning from others (in and/or outside the organization) of what they do better (products, services, processes etc.), and then skilful and creative linking of the newlyacquired knowledge with the prior organizational knowledge and implementation of new, innovative solutions aimed at improving the performance.

On the basis of: what (subject matter of the analysis), how (used methodology) and with whom (type of participants) is compared, the different benchmarking types can be distinguished. The most general classification divides benchmarking types into internal and external. Internal benchmarking is a process of comparing operations occurring within the company. Organization that uses internal benchmarking has relatively easy access to all the data and possesses full rights to the newly developed solutions. External benchmarking involves comparing own solutions with solutions utilized outside the company. The compared entity can be a direct market competitor (competitive benchmarking), a different company operating in the industry albeit not a direct competitor (functional benchmarking) and an organization operating in a different industry (generic benchmarking). When choosing the partner of benchmarking, one must take into account the subject of benchmarking, the availability of information on solutions used in other organizations, and the legal issues related. The literature describes also the so-called strategic benchmarking which: "seeks to identify the winning strategies that have enabled high-performing companies to be successful" (Kulmala, 2014).

The reason for using benchmarking is the benefits it brings to companies and their stakeholders. It provides an external focus for internal activities; utilizes existing knowledge on the effectiveness of particular processes; provides a systematic approach to quality improvement; identifies new ideas and technologies; exposes the need for change; establishes the extent of improvement required; demystifies and encourages change; provides a framework for change; decreases subjectivity in decision making; legitimizes targets by basing them on hard data; enables the incorporation of best practices' into one's company; encourages a learning culture; promotes contacts and networks (Meade,1998). In order to bring benefits to the organization the process of benchmarking should be well thought-out and properly structured.

However, benchmarking should not be treated as a miracle cure for organizational problems but as an innovative process. The aim of benchmarking is not to seek the ideal solution because such solutions do not exist. The solution that works well in one organization does not have to be the best solution for a different organization. An additional problem is also selection of the best entity for comparison (benchmarking), because there is no perfect indicator that would unambiguously identify such a partner. A different challenge is in many cases obtaining reliable information on partner's processes and their characteristics. For obvious reasons it is particularly difficult to carry out competitive benchmarking. Another challenge is that any comparison between partners is made using the parameters that define a certain state which exists at a given time, and therefore provides little information on how to reach the observed state. Achievement of a particular state results from interaction of numerous factors, of which not all can be identified. Therefore, attempting to reach a particular desired state is, sometimes, simply impossible.

Further consideration will be devoted to process benchmarking, which focuses on work processes and operating practices.

\subsection{From organizational vision to KM processes benchmarking}

Decision on performing a benchmark of knowledge management processes must be well-researched and based on sound foundations, and cannot be realized ad hoc or in manner of an accidental activity. The scheme presented in Figure 1 presents the path leading from the organizational vision and goals to making a decisions to optimize knowledge management processes by benchmarking.

All decisions and actions taken in an organization, including those related to KM processes, must be adhere to the vision and the strategic objectives of the company. Therefore, creation (or analysis, if created) of the organizational vision and goals serves as a starting point for further considerations.

Then organization should identify and classify all resources at its disposal, and determine which are of strategic nature - valuable, unique, difficult to replace or imitate. Although the following analysis is aimed at internal areas of the company, it must be supported by knowledge of the organization's environment. Starting from analysis of all the company resources is justified because knowledge gains special significance in the process of shaping organization's 
competitiveness once it was connected with the other strategic resources.

Not all types of knowledge are equally important for achieving and/or maintaining an organization's competitive advantage. Therefore the next step is identification and classification of knowledge resources, which leads to selection of strategic knowledge. At this stage it is necessary to define which types of organizational knowledge have the characteristics of strategic resources.

Figure 1. From vision to knowledge management processes benchmarking

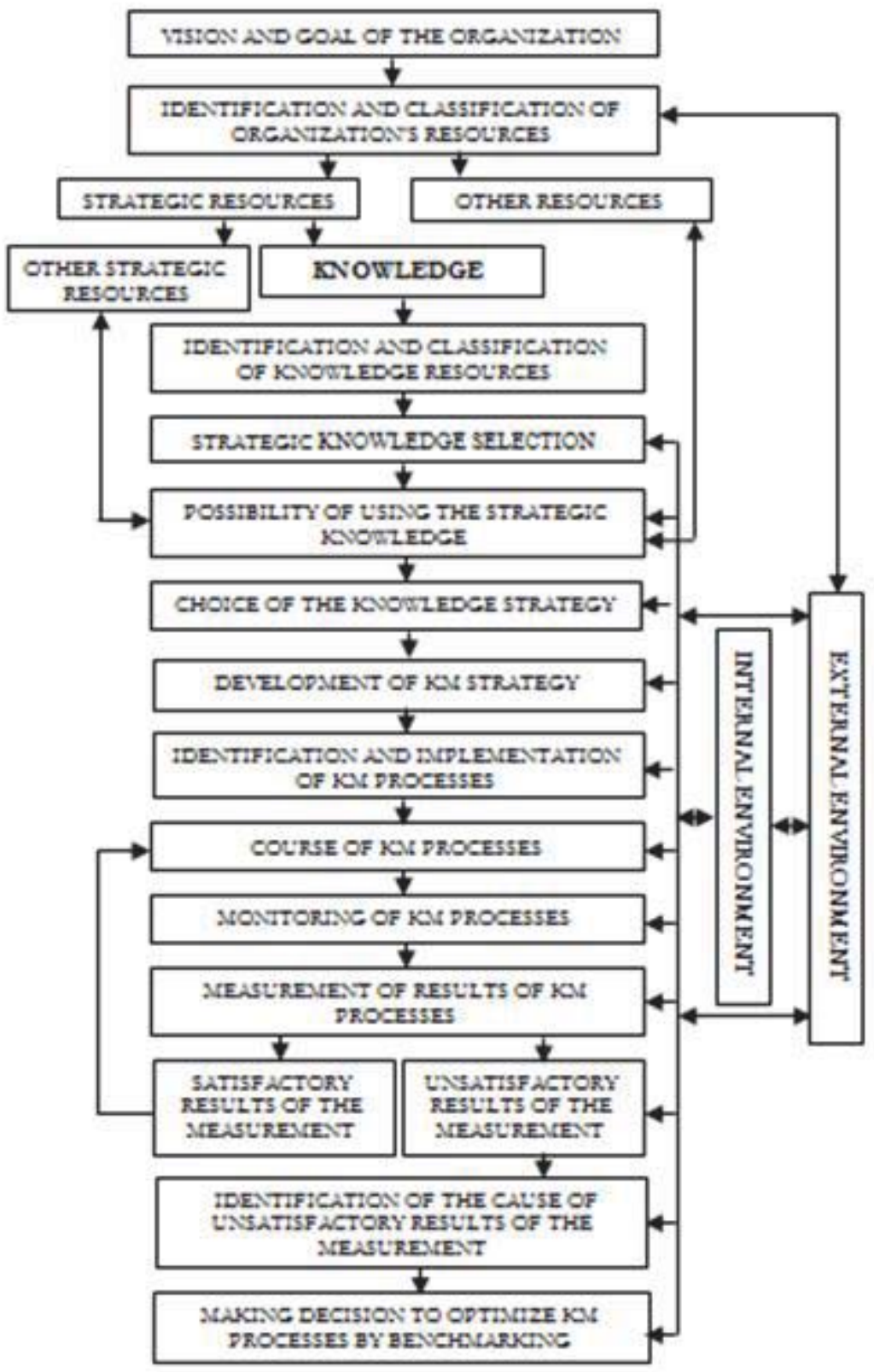

Source: Individual compilation based on study results.

Then organization should determine the possibility of using strategic knowledge in creation of offers (goods, services, processes etc.) that would be highly rated by the market. The methods of using strategic knowledge depend on possibilities and manners in which it is uniquely connected to other strategic and non-strategic resources - which consequently enables the organization to create unique offers.

The next step is selection of strategy of knowledge presenting constant, purposeful and considered influence on 
knowledge, open to new circumstances, shaping the competitiveness of the organization. Knowledge strategy is the base for creation of a KM strategy, which presents the way the organization intends to acquire and use knowledge for successful realization of its business strategy.

Subsequently, the knowledge management processes should be identified. At this stage the organization should: name processes, create processes maps and appoint their owners, determine both the processes parameters and measures of their effectiveness, as well as identify the recipient of every process. The role played by an individual process in terms of its impact on achieving the organization's objectives as well as the role played by employees in achieving the objectives of different knowledge management processes, should be communicated to all members of the company.

Identification of KM processes is the starting point for their: implementation, realization and monitoring. In the next step the results of KM processes should be measured. If the results are satisfactory, then there is no need to make changes in the processes themselves. However, if the process results are not satisfactory, then the causes should be identified. When analysing the reasons for unsatisfactory results of KM processes, the impact of both intra-organizational factors and external environment on these results must be taken into account. In many cases the lack of success of the KM processes are not the mistakes made by the organization, but changes taking place in the business environment, such as: actions taken by competitors, legal changes, etc. Determination of reasons for unsatisfactory effects is a starting point for making a decision to optimize the KM processes using benchmarking.

\subsection{Knowledge management processes benchmarking model}

Specificity of benchmarking of knowledge management processes results from the nature of knowledge. The effectiveness of KM processes is determined, to a large extent, by the elements that are difficult to observe and copy, such as: core values, norms, customs, trust, and the tacit knowledge of employees.

Benchmarking of knowledge management processes is not a simple copying of solutions that have worked for other organizations. Each solution is based on the specificity of the organization, knowledge of employees, and the pathways to specific solutions which are difficult to observe and copy. Therefore it should be kept in mind that benchmarking of KM processes is itself a creative process and should result in creation of something completely novel.

When looking for specific solutions it is advisable to use a framework to define a step-by-step procedure for optimization of KM processes by benchmarking. Figure 2 presents a framework procedure for benchmarking of KM processes which increases the possibility of success. The presented framework indicates what should be done (and in what order) when developing and implementing benchmarking project in the area of knowledge management processes. Subsequent steps of the procedure are discussed below.

Identification of a problem in KM process realization. If results of a given knowledge management process are unsatisfactory it means that there is a problem to be solved. The problem may be, for example: a small number of improvement proposals, loss of important knowledge source, insufficient transparency of knowledge resources, and many more.

Analysis of the problematic KM process. The process which poses a problem must be thoroughly analyzed, both in terms of the process logic and the individual actions, parameters adopted, metrics used, resources employed, etc. The analysis should be completed with a report containing the findings of the study.

Determination of the cause of identified problem. Based on the report, the process owner (alone or together with a team or an external expert) tries to determine the cause of the problem. Let's assume that the following problem was identified: employees use the sources of knowledge too rarely. The reason for this may be: improper localization of knowledge sources, lack of information about the availability of knowledge sources, difficult access to knowledge sources, lack of motivation to use the knowledge sources, etc. Each of the causes mentioned above requires different actions to be taken. 
Figure 2. Framework of knowledge management processes benchmarking

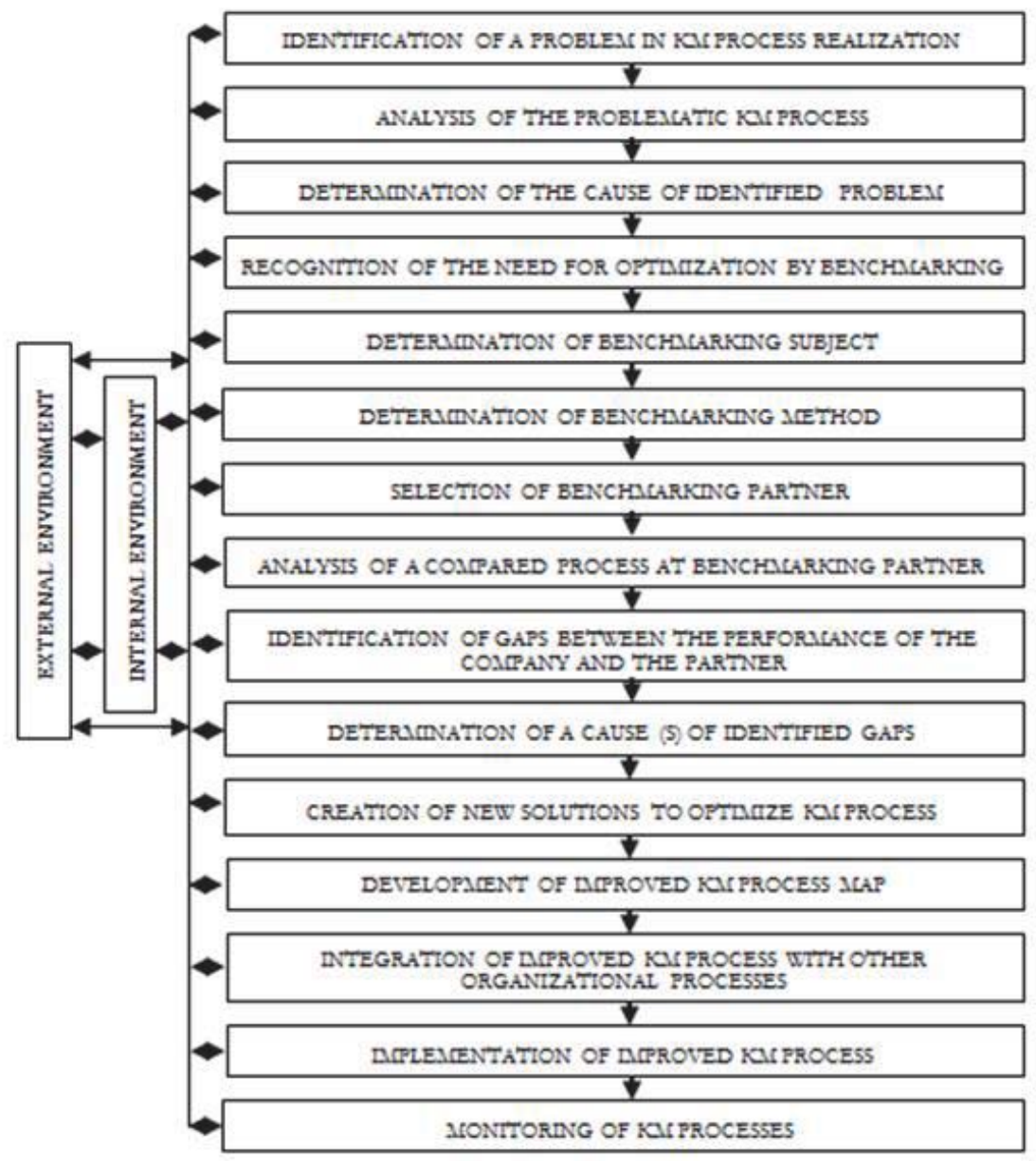

Source: Individual compilation based on study results.

Recognition of the need for optimization by benchmarking. Knowing what? (the problem) and why? (cause of the problem) it is necessary to arrive at the answer to the question of how to improve the process? At this stage, the need to introduce changes aimed at improving the process is increased and the procedure is chosen.

Determination of benchmarking subject. The subject of benchmarking may be: the logic of the process, process operations or parameters, etc. Benchmarking subject results from the nature of identified problem and the reasons for its occurrence.

Determination of benchmarking method. At this stage decision should be taken as to where to look for solutions of the identified problem - in other departments of the company, in direct or indirect competitors. In other words, the selection of the type of benchmarking (internal, external) is realized.

Selection of benchmarking partner. The choice of a partner requires answering the question of: whom do we want to learn from and who is available? Benchmarking partner may be: the best branch (department) of the company, an industry leader, or an organization which defines the standards in a particular field (marketing, logistics, public relations etc.) Making this choice requires a thorough analysis of the internal and/or external environment of the organization.

Analysis of a compared process at benchmarking partner. Carrying out such an analysis can be a very difficult task, because benchmarking partner protects knowledge determining its competitive advantage. The organization must also remember to adhere to the law. Getting information on the processes occurring at the benchmarking partner cannot stray into the realm of the industrial espionage.

Identification of gaps between the performance of the company and the partner. A comparative analysis of information on the process flow in the organization and its benchmarking partner helps to identify the gaps between the 
two entities in relation to the benchmarked processes.

Determination of a causes of identified gaps. Based on the performed analysis, the process owner (alone or together with a team or an external expert) tries to determine the causes of the identified gaps. The causes may be, for example: a different organizational culture, use of different information and communication technologies, and many other factors.

Creation of new solutions to optimize KM process. On the basis of both the newly acquired knowledge on the use of specific solutions at a benchmarking partner, and previous knowledge of the organization, new solutions are developed. They enable the organization to improve the process so that it is more efficient than before. It would be best if the improved process was more efficient than at the benchmarking partner.

Development of improved KM process map. New solutions must be placed on a modified process map. Mapping of knowledge management processes is not an easy task, because the processes tend not to fully submit to the structuring. A new process map must be clear and understandable to all people directly or indirectly involved in the implementation of the improved process.

Integration of improved KM process with other organizational processes. Knowledge management processes are inextricably linked, so any changes made in one have impact on the other KM processes, as well as on the other processes in the organization. Therefore, the improved KM process should be integrated with all the other organizational processes.

Implementation of improved KM process. Implementation of improved process requires prior communication of planned changes. Especially, the purpose of planned changes, instruction for the employees related to the scope of their duties and responsibilities should be presented. Attempts to implement any improved process without the approval of the employees can simply fail.

Monitoring of KM process. Improved knowledge management process should be monitored to in order to establish if the optimized process meets the expectations.

\section{Knowledge Development and Optimization in Creative SMEs - Practical Issues}

\subsection{Results of research}

In reference to the above-mentioned theoretical considerations, it was decided to verify them by performing a research on a group of 909 employees working in the creative sector of small and medium-sized enterprises. The survey was conducted in 2013 and its guiding idea was to demonstrate that creativity is inextricably linked to the intense work of creative human capital as well as the level of general and professional knowledge. The wider research context was presented in several publications (Sokół, 2013; Sokół, 2014) The research efforts have been undertaken in order to demonstrate that optimization of processes by benchmarking at different stages of knowledge management in organizations can contribute to generation of higher added value, and thereby to achieving greater efficiency in their functioning.

In this paper it was assumed that:

- Optimization of knowledge management processes with the use of benchmarking has positive effects on the efficiency of the company.

- Benchmarking of knowledge management processes is conductive to implementing and improving of appropriate solutions coming from other entities.

Benchmarking as a method of optimization of knowledge management processes was only one of the issues analyzed in the study. Respondents have referred to, inter alia, the reasons for implementation of KM in their organizations. From the effective KM the respondents expected mainly: improvement of the organization's competitive position (46\% of respondents), increase in the value of the company (28\%) and improvement of the organization's innovativeness (26\%). They also emphasized that proper KM allows for: increasing the flexibility of the company, reducing the uncertainty in decision-making, saving of time, effective utilization of organizational capital (human, tangible and financial), reducing the risk of knowledge loss and improves decision-making processes in companies.

Asked about the main factors motivating companies to implement KM systems, respondents listed the following factors: development of employee competence determining the successful development of the company and its growth $(32 \%)$, introduction of innovation in the company (33\%), operating costs reduction (16\%), speeding up the operation (14\%), customer satisfaction improvement (5\%).

Then respondents were asked about the sources of inspirations in both: the implementation and development of knowledge management in the company, and methods of error correction in KM processes. The most frequent sources of 
inspiration were: literature, organizational units leading in the area of $\mathrm{KM}$, other companies that manage knowledge successfully, and KM experts. The examined organizations can be said to exploit benchmarking, primarily in its internal form.

In the following considerations, references are made primarily to processes and inspirations that were drawn from other departments or organizations (e.g. best practices) in the process of creating a knowledge-based organization. A subset of selected employees was asked how to solve the current problems arising in the process of KM. Their answers were varied. After identification of the problem, the solution is sought, and, subsequently, a repair system is implemented in order to improve knowledge management. There are different ways of finding solutions to identified problems, however the first steps in the process are mostly meetings between executive staff and the employees. Within the framework of such meetings, brainstorming is the most commonly used form of problem solving (Sokół, 2014). If the problem is so serious that such activities fail to help, then the organization starts looking for: (1) a benchmarking partner, who skilfully used solutions which helped it to solve or even avoid a given problem, or (2) an expert, who due the experience gained in other knowledge-managing organizations, can be of professional help in solving the identified problems.

The study diagnosed many problems within organizational KM and discovered many elements that can be improved using experiences of other organizations (external benchmarking). The respondents most frequently pointed the following problems in their organizations: knowledge is possessed by a single group or a single person, knowledge is highly priced, knowledge is treated as a source of power, lack of knowledge where it is needed, "monopolisation" of knowledge prevents the creation of new knowledge, competition between employees, rejection of everything that has not been created by a particular person or a group, lack of proper communication infrastructure, knowledge is enclosed within the group that created it, lack of access to knowledge in the organization, hampered cooperation between teams due to the low trust level, lack of faith in people and their competences, lack of relationship between employees in the company, lack of faith in the quality of organizational knowledge, lack of openness to good ideas of employees.

Respondents were also asked whether they see the need to use other sources of knowledge. In response, they indicated that the most frequently used method to generate knowledge in their organizations was learning (both individual and group based). It seems that internet forums and chat-rooms should be developed in order to improve knowledge management processes. They allow for the unhampered exchange of views within the organization and facilitate faster transfer of knowledge. They also lead to effective, creative problem solving, and, ultimately result in generation of added value in form of: new products, services, processes, procedures, etc. Knowledge network - which is a simple form of knowledge creation - is very rarely utilized by organizations.

One of the simplest and, at the same time, most expected mechanisms of knowledge capture, transfer and development, are group tools. Other mechanisms listed in the table 1 may favour optimization of knowledge creation, but each organization must individually assess their own needs related to knowledge management processes, and adapt them to their own expectations.

Table 1. The mechanisms of knowledge acquisition in the surveyed organizations

\begin{tabular}{|c|c|c|c|}
\hline Knowledge creation & Responses & Knowledge integration & Responses \\
\hline Individual learning & $\mathbf{x}$ & Trainings & \\
\hline Group learning & $\mathbf{x}$ & Communities of practice & $\mathbf{x}$ \\
\hline Innovation management and IC & & Knowledge acquisition & xy \\
\hline Internet forums, chat rooms & y & Storytelling & \\
\hline KAIZEN & & Initiatives in the area of organizational culture & \\
\hline Think tanks & & Information portals & $\mathbf{x}$ \\
\hline Systems Network Architecture & & Intranet & y \\
\hline Knowledge network & $y$ & Information management & $\mathbf{x}$ \\
\hline $\begin{array}{l}\text { Knowledge portals } \\
\text { Innovation Management Tools }\end{array}$ & $x y$ & $\begin{array}{l}\text { Work product management } \\
\text { Content management }\end{array}$ & \\
\hline Group tools & y & Grupware & y \\
\hline - Applications to cooperate & yes & & \\
\hline$\circ \quad$ Virtual teaming tools & yes & & \\
\hline$\circ \quad$ E-mail & & & \\
\hline Discussion groups & & & \\
\hline
\end{tabular}

$X, X X$ - currently used sources of knowledge and the mechanisms of its creation and integration

$Y, Y Y$ - proposed changes to improve processes

Source: Individual compilation based on study results. 
The study confirmed the importance of motivation (reward, promotion) of employees who share their knowledge with others and take steps to facilitate knowledge creation. However, $56 \%$ of respondents stated that their superiors do not encourage knowledge-sharing among employees. According to the respondents, activities aimed at motivating knowledge sharing among employees can be optimized by introducing the following practices observed in other organizations: creation and use of appropriate tools that facilitate systematic knowledge sharing, introduction of an adequate reward systems, creation of an atmosphere that is conducive to knowledge sharing, easy and quick access to knowledge resources for all employees at all levels of the organization.

Respondents were also asked whether they were interested in knowledge on the latest technology trends. $15 \%$ of respondents were not interested in this issue at all, $12 \%$ of them had some knowledge, but it did not relate to the business profile of their organizations, $1 / 4$ of respondents were interested in and familiar with the latest technology trends, while the largest group (47\%) of surveyed population knew and used all the new technology in organizations.

The analysis of the empirical material leads to a conclusion that in optimizing the process of knowledge transfer in organizations through internal and/or external benchmarking, a number of conditions must be fulfilled: employees must have a sense of belonging to the organization's community as well as behave in a manner consistent with the requirements of the organization's culture; they have to have both the motivation and the ability for systematic learning; the employees must be customer-oriented (focused on identifying, anticipating and satisfying customer needs) as well as team-oriented (share the conviction that the basic unit of learning is a team of employees); information must be generally available; proper balance must be maintained in personalization and codification strategies; the organisation must support professional development of the employees in a systematic and organized way; and the organizational climate must be conductive to creativity and innovation, knowledge sharing, experimentation and learning from mistakes.

Another subject of analysis were the IT solutions that have been introduced in the surveyed organizations in the last 2 years in order to optimize KM processes. When it comes to frequencies, the following tools supporting KM take subsequent places: data warehouse, document management system, workflow system, groupware, corporate portals, decision support systems, and expert systems. Respondents who used IT tools to enhance the effectiveness of information and data transferring also found that application of IT tools brings various benefits to the company, such as: making better decisions, reducing time of problems solving, reducing costs, product improvements. It must be noted, however, that even the best-functioning IT systems that facilitate knowledge transfers will be useless if the employees will not use them in a way that creates added value for customers.

A final issue raised in the survey concerned the future plans related to the implementation of knowledge management systems. Almost half of the respondents expected increase of the importance of knowledge management in their organizations in the near future.

\subsection{Research conclusions}

In the conclusion of the study it must be noted that optimization of knowledge management processes through benchmarking is often used and has been proven an effective method. Research has shown that benchmarking can improve knowledge processes in the organization - generating higher added value for the company and, simultaneously, affecting its competitiveness. It can, therefore, be said that the optimization of these processes is conducive to development of an company and its employees, because both function as a better integrated system.

Implementation and optimization of KM processes basis of external sources should take into consideration the following: selection of leaders who are able to encourage others to share their knowledge and provide them with all the support, selection of the most effective ways of knowledge sharing for the actual organisational structure, introduction of appropriate incentive systems which would encourage sharing of knowledge, development of contacts conducive to knowledge sharing, creation of appropriate conditions, i.e. place and time for knowledge sharing, linking knowledge sharing with the organizational values, determination of how the knowledge sharing is associated with the objectives of the company. In addition, the climate of trust, proper working atmosphere, lack of destructive competition and availability of information to all concerned are important factors for KM processes optimization by benchmarking.

An appropriate incentive system enables employees to understand the importance of knowledge generation and transfer and encourages them to engage in such processes. However, for active and creative employees who are engaged in the processing and use of knowledge the motivation becomes an essential factor.

\section{Conclusions}

By identifying industry standards or how given knowledge management processes are realized in other companies, 
stakeholders gain new insights and ideas, which when combined with their previous knowledge can contribute to finding completely new, creative solutions, which will allow the organization to increase its competitiveness in the market. As it was already stated, properly conducted benchmarking of knowledge management processes can bring many benefits to the organization, while improperly conducted can bring about its failure on the market. However, optimization of knowledge management processes through benchmarking is a complex problem. The following article doesn't deplete the topic and is only a basis for further considerations.

\section{References}

Blakeman, J. (2002). Benchmarking: Definitions and Overview, Center for Urban Transportation Studies, University of Wisconsin Milwaukee. [Online] Available: https://www4.uwm.edu/cuts/ bench/bm-desc.htm (July 15, 2014)

Dalkir, K. (2005). Knowledge Management in Theory and Practice. Elsevier Butterworth Heinemann Publishers, 372.

Figurska, I. (2007). Rozwijanie wiedzy pracowników w organizacjach w teorii i praktyce (Development of workers' knowledge in organizations in theory and practice). In. Zarządzanie kapitałem ludzkim w gospodarce (Management of human capital in the economy). D. Kopycińska (ed.), Szczecin, University of Szczecin Press, 65-73.

Figurska, I. (2009). Knowledge management obstacles in theory and practice. In. Manažment ludskeho potenciálu v podniku, M. Blaskova, J. Suchomel (ed.). Żylina, Univeristy of Żilina Press, 19-29.

Figurska, I. (2012). Zarządzanie wiedzą w organizacji (Knowledge management in the organization). Słupsk, WHSZ Publishers, 397.

Hammer, M., \& Champy, J. (1993). Reengineering the Corporation: A Manifesto for Business Revolution. New York, HarperBusiness Publishers, 259.

Hammer, M. (1999). How process enterprises really work. Harvard Business Review. (November-December), 108-118.

Kelessidis, V. (2000). Benchmarking. Report produced for the EC funded project INNOREGIO: issemination of innovation and knowledge techniques, [Online] Available: http://www.adi.pt/ docs/innoregio_benchmarking-en.pdf (33) (August 20, 2014).

Kowalczyk, A., \& Nogalski, B. (2007). Zarządzanie wiedzą. Koncepcja i narzędzia (Knowledge management. Concept and tools). Warsaw, Difin Publishers, 222.

Kulmala, J. (2014). Approaches to benchmarking, Finnish Employers' Management Development Institute, FEMDI. [Online] Available: http://www15.uta.fi/yksikot/entrenet/hankerekisteri /hanke5_benchmarking.htm (August 20, 2014).

Lockamy III, A., \& McCormack, K. (2004). The development of a supply chain management process maturity model using the concepts of business process orientation. Supply Chain Management. (9) 4, 272-278.

Meade, P. H. (1998). A Guide to Benchmarking. University of Otago, 24.

Mikuła, B. (2006). Organizacje oparte na wiedzy (Knowledge-based organizations). Kraków, Univeristy of Economics Publishers, 255.

Murray, P., Myers, A. (1997). The Facts About Knowledge. Special Report. Information Strategy (2) 7, 29-33.

Pfeffer, J., \& Sutton, R.I. (2002). Wiedza a działanie (The knowing doing gap). Cracov, Office of Economics Publishers, 237.

Probst, G. (2004). Zarządzanie wiedzą w organizacji (Knowledge management in the organization). E-mentor, (3) 5, 18-20.

Probst, G., Raub, S., \& Romhardt, K. (2002). Zarządzanie wiedzą w organizacji (Knowledge management in the organization). Cracov, Office of Economics Publishers, 352.

Sarvary, M. (1999). Knowledge management and Competition in the Consulting Industry. California Management Review. 95-107.

Skyrme, D.J. (2002). Knowledge Management: Approaches and Policies. [Online] Available: http/www.skyrme.com (May 15, 2014).

Skyrme, D.J. (2003). Knowledge Management: making sense of an oxymoron. [Online] Available: http/www.skyrme.com (May 15, 2014).

Sokół, A. (2013). Empirical verification of imaginative attitudes in creative enterprises of the SMEs sector. In. Enterprise development strategies in the knowledge- based economy, A. Budziewicz, A. Drab- Kurowska, K. Drela, A. Sokół (eds.), Series: Modern challenges of economic entities. New York, Iglobal Writer Inc Publishers, 20-45.

Sokół, A. (2014). The workers' influence on the success of creative enterprises - creative workers and knowledge workers. In. 1st International Scientific Conference for PhD students of EU countries, CER Comparative European Research, London, Scieemce, 72-78.

Walsh, J.P., \& Ungson, G.R. (1991). Organizational Memory. The Academy of Management Review. (16) 1, 57-91.

Wiig K.M. (1993). Knowledge management Foundations: Thinking About Thinking - How People and Organizations Create, Represent, and Use Knowledge. Arlington, TH: Schema Press, 471.

Wiig K.M. (1999). Introducing knowledge management into the enterprise. In. Knowledge Management Handbook, J. Liebowitz (ed.). Boca Raton, CRC Press:, 3-1.

Wood, B. (2009). 7 Steps to Better Benchmarking, Business Performance Management, [Online] Available: http://businessfinancemag. com/business-performance-management/7-steps-better-benchmarking-0 (August 14, 2014). 